\title{
O DIREITO FUNDAMENTAL À IGUALDADE E O PRINCÍPIO DA SOLIDARIEDADE COMO FUNDAMENTO CONSTITUCIONAL PARA AS AÇÕES AFIRMATIVAS
}

\section{FUNDAMENTAL RIGHT TO EQUALITY AND THE PRINCIPLE OF SOLIDARITY AS CONSTITUTIONAL BASIS FOR AFFIRMATIVE ACTIONS}

\author{
${ }^{1}$ Iuri Bolesina \\ ${ }^{2}$ Tássia Aparecida Gervasoni
}

\section{RESUMO}

Este trabalho visa investigar os fundamentos constitucionais para as ações afirmativas e cotas em um Estado Democrático de Direito. Para tanto, dedicar-se-á ao exame de dois possíveis fundamentos: o direito fundamental à igualdade e o princípio constitucional da solidariedade. Firmados esses pressupostos, será enfrentada a discussão acerca das ações afirmativas, especificamente as reservas de cotas, buscando elucidar argumentos favoráveis e contrários comumente apresentados a essas ações, já sob à luz dos fundamentos estabelecidos na primeira parte do estudo. Como metodologia, utiliza-se o método de abordagem da fenomenologia hermenêutica, o método de procedimento monográfico e a técnica de pesquisa documentação indireta.

Palavras-chave: Ações afirmativas, Igualdade, Solidariedade

\begin{abstract}
This paper will investigate the constitutional basis for affirmative action and quotas in a democratic state. It will be examined two possible reasons: the fundamental right to equality and the constitutional principle of solidarity. Established these assumptions, it will faced the discussion about affirmative action, specifically the reserves of quotas, seeking to elucidate arguments for and against commonly given to these actions, as in the light of the grounds set forth in the first part of the study. The methodology used is the hermeneutic phenomenology approach method, the monographic procedure method and the indirect documentation search technique.
\end{abstract}

Keywords: Affirmative action, Equality, Solidarity

\section{Introdução}

1 Doutorando em Direito pela Universidade de Santa Cruz do Sul. Advogado. Universidade de Santa Cruz UNISC, Rio Grande do Sul. Brasil - E-mail: iuribolesina@gmail.com

2 Doutora em Direito pela Universidade do Vale do Rio dos Sinos. Advogada. Universidade do Vale do Rio dos Sinos - UNISINOS, Rio Grande do Sul. Brasil - E-mail: tassiagervasoni@ gmail.com 
Um Estado que se adjetiva como Democrático de Direito, como faz o brasileiro, deve promover a pluralidade, a igualdade e a solidariedade, prestigiando a diversidade e combatendo a desigualdade. Para que isso ocorra de modo abrangente, torna-se imperiosa e urgente a discussão relativa a práticas que possam, efetivamente, conduzir a resultados nesse sentido.

Visando à construção de um estudo voltado para essa questão, o presente artigo articulase em duas partes de desenvolvimento. A primeira delas voltar-se-á para o direito fundamental à igualdade e para o princípio constitucional da solidariedade, objetivando-se um estudo composto destes elementos jurídicos. Em geral, tem-se como lugar comum invocar o direito fundamental à igualdade como norteador dos debates acerca das ações afirmativas, olvidandose que a igualdade ganha novas matizes de diversidade e pluralidade quando interpretada a partir da solidariedade. É entorno da igualdade como solidariedade que se pretende trabalhar.

Na sequência, o artigo debruçar-se-á sobre a discussão que orbita as ações afirmativas, especificamente as (reservas de) cotas, notadamente em âmbito educacional e profissional. O texto, nesse sentido, buscará elucidar os argumentos prós e contra as cotas, tendo como referência a celeuma nascida do debate das cotas raciais. A referência será no sentido de contextualizar os argumentos, não pretendendo-se instaurar um debate sobre racismo(s) e antirracismo(s). Como o foco residirá nos argumentos, buscar-se-á aclará-los com base nos cenários brasileiro e norte-americano, evidenciando, também, os julgados sobre a constitucionalidade e alguns números obtidos posteriormente à implementação das cotas.

Em termos de metodologia, o presente trabalho adotará uma abordagem fenomenológico-hermenêutica, utilizando-se do método de procedimento monográfico e da técnica de pesquisa da documentação indireta.

\section{Revisitando o direito fundamental à igualdade e o princípio da solidariedade}

São elementos comuns nos Estados democráticos a presença do direito fundamental à igualdade e o princípio da solidariedade nas Constituições, os quais, também, costumam aparecer conjuntamente na fala dos especialistas, expressando que são complementares em certa medida. Paradoxalmente, essa menção não é proporcional. Em uma obra que vá tratar da igualdade, a solidariedade aparece como reforço argumentativo e o inverso pode-se afirmar de uma obra que dedique seu núcleo à solidariedade. Efetivamente, são poucos os textos que irão tratá-las em grau de paridade, o que é fundamental para o presente estudo. Para tanto, propõe- 
se revisitar os direitos/deveres acima mencionados, no sentido de se realizar inicialmente uma exposição histórica desses direitos em separado e, na sequência, voltar-se para uma perspectiva crítica e conjunta desses direitos e da sua contextualização contemporânea.

Quanto ao direito à igualdade, nota-se tratar-se de uma pauta que historicamente sempre esteve à mira dos sistema jurídicos (demonstrando que a desigualdade identicamente sempre fez-se presente), os quais, cada qual a seu tempo, buscaram interpretá-lo e aumentar o grau de certeza na sua concretização. Ironicamente, não obstante tal desiderato, as Constituições não costumam elaborar uma digressão mais específica e contextual do direito à igualdade - como ocorre, por exemplo, com o direito à igualdade que é esmiuçado quase que didaticamente (BONAVIDES, 2009, p. 217-218).

Historicamente, costuma-se indicar como nascedouro do direito fundamental à igualdade o advento do Estado Constitucional Liberal, de cariz minimalista e moderna, notadamente como exemplo o Estado Francês formatado com o sucesso da revolução francesa. Nesse período, uma das promessas dos revolucionários burgueses era a ideia de igualdade para todos, indistintamente. Representava, pois, um direito que assegurava que todos fossem iguais formalmente, em oportunidades, portanto.

Tal lógica estruturava-se majoritariamente sobre os princípios da igualdade formal - a qual vendeu a expectativa de que todos poderiam ter sucesso já que eram iguais perante a lei, instalando o que se convencionou chamar de darwianismo social - e da dicotomia do público e do privado - que simbolizou existir um espaço que não dizia respeito ao Estado (o privado) e outro que era de interesse reservado do Estado (o público). No dizer de Bobbio (2010, p. 1315), entedia-se que um excluía o outro: o que não era privado era público e vice-versa.

A insustentabilidade desse modelo apareceu no decorrer do século XIX e início do XX. Reis (2008, p. 132) ilustra adequadamente o momento, aduzindo que o sistema liberal passou por dois períodos distintos: um da conquista da liberdade e outro da exploração da liberdade. As transformações sociais nesse mesmo espaço (europeu), no interstício das Revoluções Industriais, pautadas pelo agravamento das desigualdades e das situações de vulnerabilidade social, e motivadas em boa medida pelo argumento da igualdade material e da meritocracia, conduziram a mudanças de ordem constitucional (BARCELLOS, 2007, p. 101).

A edificação de uma constitucionalidade de cunho social, de inclinações ao bem-estar social, alterou a percepção dos Estados no que tange ao direito à igualdade, impondo-lhes deveres de cunho prestacional, mirando-se a igualdade material, ou seja, além das mesmas 
oportunidades, isonômicas condições. Como bem se sabe, tais obrigações eram bastante restritas e encaradas como politicamente programáticas (na medida (da reserva) do possível). A igualdade material traz consigo o desenvolvimento de programas governamentais que miram suprir os nichos mais críticos de desigualdades, sendo estes programas chamados de ações afirmativas (CARVALHO, 2010, p. 829).

As constituições contemporâneas de índole democrática, ao preceituarem o direito fundamental à igualdade, buscam efetivá-lo em sua dupla dimensão: formal e material. No Brasil, por exemplo, a igualdade vem constitucionalmente assegurada em diversas passagens, mas especialmente nos arts. $3^{\circ}$ e $5^{\circ}$ (com seus respectivos e pertinentes incisos), os asseveram, respectivamente, que é objetivo do Estado brasileiro a redução das desigualdades; e que a todos há igualdade na lei, perante a lei.

Por seu turno, o princípio da solidariedade era historicamente desprovido de normatividade jurídica. Suas expressões davam-se no âmbito dos valores (especialmente cristãos), sendo encarado como um sinônimo da fraternidade (e não raro da caridade) (GÓRIA, 2012, p. 27). A noção jurídica da solidariedade somente começa a aparecer - de modo muito incipiente - nos anos que antecederam e no período posterior à Revolução Francesa (1789), estando vinculada/equiparada de forma direta à fraternidade. Surge primeiro como princípio político-jurídico ideal a uma república, postando-se ao lado da liberdade e da igualdade e, em seguida, como baluarte revolucionário esquecido pelas Constituições liberais, que apenas reaparece com força renovada ao longo do fervilhar das revoluções industriais e dos Estados sociais (BAGGIO, 2008, p. 7-9).

Nos séculos XIX e XX, a solidariedade é empoderada, servindo inicialmente como um dos fundamentos para os pleitos veiculados nas revoluções sociais e industriais que eram direcionados ao Estado, notadamente visando a reestruturação do Estado sob traços mais sociais e menos liberais/individuais (GARCIA-PELAYO, 1996, p. 14). Para tanto, percebe-se que a liberdade e principalmente a igualdade impulsionam e são impulsionadas pela solidariedade, formando um movimento circular de concretização.

Com o advento dos Estados Democráticos de Direito, a solidariedade, enquanto princípio jurídico, é elevada a elemento de hierarquia legal superior. No Brasil, sua previsão dáse expressamente no art. $3^{\circ}$, I, da Constituição Federal, sendo dotada, portanto, de uma dobra de sentido: por um lado sendo um dos princípios fundamentais e, por outro lado, se constituindo em um dos objetivos fundamentais do Estado brasileiro. 
$\mathrm{Na}$ teoria contemporânea dos direitos fundamentais, o princípio da solidariedade, visto como um direito/dever, é lido como de terceira dimensão, o qual, além de possuir força normativa própria, dá azo a outros direitos e deveres mais específicos - como autodeterminação dos povos, meio ambiente e qualidade de vida e comunicação, dentre outros - que estão difusos pelo ordenamento jurídico (SARLET, 2010, p. 48).

Há certo consenso de que é hercúleo e igualmente ingênuo tentar fechar ou definir taxativamente um conceito do princípio constitucional da solidariedade. Em verdade, qualquer tentativa nesse sentido peca por restringir as potencialidades que tal princípio possui. Isso não significa, contudo, que o princípio da solidariedade não possua traços elementares, linhas mais grossas do que venha a ser e do que possa fazer. Tampouco quer dizer que esse princípio seja a panaceia para todo e qualquer problema político ou jurídico. Daí porque se possa dizer, em sentido bastante amplo, que o princípio da solidariedade se traduz no "atuar humano, de origem no sentimento de semelhança, cuja finalidade objetiva é possibilitar a vida em sociedade, mediante respeito aos terceiros, tratando-os como se familiares o fossem; e cuja finalidade subjetiva é se auto-realizar, por meio da ajuda ao próximo" (AVELINO, 2005, p. 250).

Juridicamente, o princípio constitucional da solidariedade impõe direitos/deveres que jungem numa terceira via as posições, geralmente opostas, de individualismo exacerbado e, de outro lado, de hegemonia do social (PERLINGIERI, 2008, p. 47; CARDOSO, 2010, p. 93). É o que se reconhece academicamente como "solidarismo jurídico"1. Dito isso, é pertinente sublinhar que atualmente resta evidenciada a distinção entre solidariedade jurídica e fraternidade. A diferença reside no aspecto de que a solidariedade diz respeito às ações, ao passo que a fraternidade trata das ações e das intenções (SILVA, 2008, p. 418). 
Significa dizer, em outros termos, que uma pessoa pode ser solidária sem que seja fraterna, aparecendo, talvez, como melhor exemplo disso a solidariedade no âmbito tributário do imposto de renda e da redistribuição de renda ou da justiça social. A noção de ações afirmativas, destarte, encaixa-se neste contexto, uma vez que busca elaborar uma tutela legal e política em prol de grupos minoritários (não em número, mas em termos de discriminação sociocultural e legal-institucional), fundada também no ideal de solidariedade.

Agora, superada a análise histórica, pertinente elaborar-se a contextualização crítica destes elementos, no cenário que privilegia o tema tratado neste estudo, qual seja, as ações afirmativas. Adiante.

Hodiernamente, a ideia de igualdade é comumente relegada a duas afirmações: a primeira, usualmente presente nas Constituições, geralmente sobre expressão "todos são iguais perante à lei" - que, ao fim e ao cabo, trata-se de uma afirmação universalizante (formal), genérica e pouco atenta às singularidades - . No Brasil, tal previsão constitucional vem estampada no art. $5^{\circ}$, caput. A segunda aparece plasmada no vetusto adágio "tratar igualmente os iguais e desigualmente os desiguais, na exata medida de suas desigualdades" (NERY JÚNIOR, 1999, p. 42) - que, por seu turno, é mais atenta às singularidades (material), aliada da aspiração de justiça, mas ainda assim genérica. Falta, pois, em ambas as afirmações, o enfrentamento crítico de uma questão pré-existente e determinante: a(s) desigualdade(s).

\footnotetext{
1 “A pessoa é inseparável da solidariedade: ter cuidado com o outro faz parte do conceito de pessoa. O solidarismo é suscetível de uma pluralidade de significados [...] "A diversidade de acepções torna oportuno colher a relevância e o valor do solidarismo no sistema constitucional. [...] Nesta perspectiva, a solidariedade exprime a cooperação e a igualdade na afirmação dos direitos fundamentais de todos, não solidariedade restrita nos confins de um grupo, nem dissolvida na subordinação de cada um ao Estado: 'a solidariedade constitucional não concebe um interesse superior ao pleno e livre desenvolvimento da pessoa.” (PERLINGIERI, 2008, p. 461-462).
} 
Inicialmente, note-se que a igualdade é um direito "refletido", pois sempre depende de um segundo objeto de análise (um parâmetro de observação). Sobressai-se, assim, a necessidade de localizar a fala, visando responder ao menos três aspectos: igualdade em quê? Igualdade para quem? E, igualdade para quê? (OPPENHEIM, 1998, p. 597-598). Nesse sentido, vale a anotação de Bobbio (2000, p. 12/16), ao demonstrar que a igualdade só faz sentido se criticamente contextualizada:

[...] a igualdade é pura e simplesmente um tipo de relação formal, que pode ser preenchida pelos mais diversos conteúdos. Tanto isso é verdade que, enquanto $\mathrm{X}$ é livre é uma proposição dotada de sentido, $\mathrm{X}$ é igual é uma proposição sem sentido, que, aliás, para adquirir sentido, remete à resposta à seguinte questão: igual a quem? [...] Que duas coisas sejam iguais entre si não é nem justo nem injusto, ou seja, não tem nenhum valor em si mesmo, nem social nem politicamente. Enquanto a justiça é um ideal, a igualdade é um fato. Não é em si mesmo nem justo nem injusto que duas bolas de bilhar sejam perfeitamente iguais entre si. A esfera de aplicação da justiça, ou da igualdade social e politicamente relevante, é a das relações sociais, ou dos indivíduos ou grupos entre si, ou dos indivíduos com o grupo (e vice-versa).

A perspectiva de igualdade presente na maioria dos países democráticos e capitalistas conduz à noção de meritocracia e de satisfação das diferenças por meio de justiça distributiva. Diversas das teorias da justiça que se propuseram a enfrentar a questão da igualdade o fizeram sempre aceitando a desigualdade, desde que essa adviesse dos esforços pessoais de cada pessoa, ou seja, da meritocracia. Isso as torna paradoxais, pois defendem a igualdade promovendo a desigualdade (DISSENHA, 2014, p. 54). A meritocracia, como se verá adiante, é em verdade uma ilusão ${ }^{2}$.

\footnotetext{
2 "Está claro que a igualdade de possibilidades não existe mais. A ideologia do mérito, da virtude, da igualdade de possibilidades, não pode servir para reconstruir sociedades. Por isso critiquei as chamadas teorias da justiça, Essas teorias, inclusive entre aqueles que apresentam sua versão mais progressista, como o prêmio Nobel de Economia Amartya Sem ou John Rawls, seguem inscritas em uma filosofia das desigualdades aceitáveis enquanto essas desigualdades estejam articuladas em torno do mérito, da ação do indivíduo. Esse não é o modelo da boa sociedade. O modelo da boa sociedade não é a meritocracia. [...] O grande sociólogo britânico Michael Young foi o primeiro a falar nos anos 60 da meritocracia, que é um velho ideal dos séculos XVIII e XIX. Young definia como um pesadelo todo país que fosse governador pela meritocracia. E é um pesadelo porque, neste caso, ninguém teria direito a protestar contra as diferenças. Se todas as diferenças estão fundadas sobre o mérito, aquele tem uma condição inferior a tem por culpa própria. Trata-se então de uma sociedade onde a crítica social não teria mais lugar." (ROSANVALLON, 2012b).
} 
Pierre Rosanvallon (2012a) é atualmente um dos grandes críticos deste sistema. Para ele, ao mesmo tempo que a igualdade é pauta recorrente nos debates sobre justiça social, os esforços concretos para efetivá-la nunca foram tão rasos. Da mesma forma, concomitantemente ao aumento das lamúrias e do sentimento de se conviver em uma sociedade injusta, tem-se o aumento da tolerância para com as desigualdades. Esse contexto Rosanvallon acusa de ser um contrassenso, na verdade, um Paradoxo de Bossuet, pois: "los hombres se lamentan en general de aquello que aceptan en particular". Tal menção dá-se quanto ao fato de que as pessoas, em geral, rechaçam as desigualdades, mas aceitam os mecanismos que as produzem, especialmente se há uma relação com questões de diferença de mérito socialmente aceitas (ROSANVALLON, 2012a, p. 15-17). Destarte, o primeiro passo para a reinterpretação da igualdade é opor-se à desigualdade, advenha ela de onde advier.

Por outro lado, a ideia contemporânea de igualdade, vivenciada na maioria dos estados democráticos-capitalistas, afastou-se do espírito revolucionário (calcado na semelhança, na independência e na cidadania) que lhe era próprio na sua origem. Hoje, a noção de igualdade é muito próxima das questões patrimoniais e de acesso ao patrimônio. Impera relacionar-se com a igualdade menos como a redistribuição das riquezas, e mais como uma relação social em si. Mostra-se necessário, na visão de Rosanvallon (2012a, p. 316-317) resgatar a o espírito revolucionário da igualdade, que, atualmente, irá apresentar-se nas vestes da igualdade como solidariedade, privilegiando questões de comunalidade (communalité) - construção conjunta da sociedade com base na reciprocidade e da singularidade. A singularidade aqui:

\begin{abstract}
[...] não se confunde com autonomia ou identidade. A autonomia é determinada por uma variável de posição, estática na essência. A identidade, por variável de constituição, é essencialmente dada, ainda que possa evoluir com o tempo. A singularidade é definida por uma variável de relação, não é um estado. A diferença é, neste caso, o que liga e não o que separa, pois, a igualdade da singularidade somente se manifesta na coexistência (pelo querer conhecer as diferenças dos outro com relação às nossas) $\mathrm{e}$, assim, implica, ao contrário, que cada indivíduo se manifeste por aquilo que é. $\mathrm{O}$ fato da diversidade é neste caso a medida da igualdade. Isso significa que cada um pode encontrar seu caminho e se tornar senhor de sua história, que cada um é de forma parecida único (DISSENHA, 2014, p. 58).
\end{abstract}

Então, enquanto Rosanvallon (2012a, p. 351) questiona: “¿Cómo ser semejantes y singulares, iguales y diferentes, iguales en unos aspectos y desiguales en outros?”, Boaventura de Souza Santos (1999, p. 61) responde: "temos o direito de ser iguais sempre que a diferença nos inferioriza; temos o direito de ser diferentes sempre que a igualdade nos descaracteriza". 
Significa, portanto, que a igualdade como solidariedade une as perspectivas de diversidade e reciprocidade, visando a construção sinérgica da sociedade ${ }^{3}$, enfrentando o fato de que, ao mesmo tempo em que a democracia se afirma como regime ela morre como forma de sociedade sob o peso da desigualdade (ROSANVALLON, 2012a, p. 11). Assim, a solidariedade que encapa a igualdade é mais acentuada que a sua visão tradicional. Não se trata de ser solidário por fins de imposição legal meramente ou por motivos de risco à condição humana do outro; é, na verdade, um ser solidário no sentido comunal com todos os semelhantes, independentemente de sua classe, sexo, nacionalidade ou qualquer outro adjetivo culturalmente criado, mirando sua condição humana (ROSANVALLON, 2012a, p. 363).

A anotação de Hanna Arendt (1989, p. 335) de que "não nascemos iguais, tornamo-nos iguais como membros de um grupo por força da nossa decisão de nos garantirmos direitos reciprocamente iguais" é, neste sentido, pertinente e uníssona com Rosanvallon. A igualdade, enquanto previsão, nada mais é do que um conceito, um reflexo da cultura naturalizada em determinada sociedade. É a sua interpretação, de acordo com a vontade constitucional, que torna possível a igualdade contextualizada. Destacável, aqui, a provocação de Davi Sánchez Rubio (2012, p. 15), que questiona quantos direitos são violados diariamente, mas não chegam a ser tutelados ou, pior, sequer alcançam o reconhecimento/nível de violação, não obstante a positivação de inúmeros instrumentos jurídicos de proteção e/ou promoção.

Logo, as relações que envolvem diretamente o direito à igualdade, além de sempre serem interpretadas pelo viés da solidariedade, também carecem de análise individualizada (ROSANVALLON, 2012a, p. 356). Torna-se, dessa forma, a interpretação da igualdade algo contextual e não conceitual. Isso significa que o aprisionamento do direito à dogmática ou aos conceitos clássicos da modernidade impede a análise dinâmica que demanda o direito à igualdade em face de incontáveis questões de complexidade próprias do tempo presente.

\footnotetext{
3 "Se observamos as utopias escritas nos séculos XVIII e XIX, toda a visão da igualdade está fundada sobre a ideia de uma homogeneidade, ou seja, todo o mundo tem que se parecer. Para esses utópicos, a ideia comunista, no sentido comunitário que plasma a igualdade, era uma ideia fundada sobre o fato de que todo o mundo se parecia, de que todos trabalhavam em um mesmo marco. Foi o que se chamou, em uma determinada época, de uma espécie de igualdade de posição ou igualdade da uniformidade. Essa visão correspondeu a uma idade da humanidade, mas hoje quem gostaria de uma igualdade desse tipo, de uma igualdade que negasse a diferença entre os indivíduos? Esses utópicos não queriam as diferenças entre os indivíduos. Queriam que todo mundo vivesse no mesmo ritmo, que todos fossem, de alguma maneira, o duplo dos demais. Mas não é assim. Creio que a emancipação humana passa hoje pela condição de que cada pessoa seja reconhecida pelo que tem de específico. Por conseguinte, a igualdade não pode ser mais a uniformidade, nem a uniformidade de posição, mas sim uma igualdade da singularidade." (ROSANVALLON, 2012b).
} 
Significa, também, que a igualdade jurídica por vezes se revela na desigualdade fática, notadamente quando voltada para promoção de direitos fundamentais (FRISCHEISEN, 2007, p. 133-134). Nesse sentido, um exemplo adequado é a possibilidade de discriminação legal, desde que amparada nos intentos da Constituição e, portanto, sendo deferente à proporcionalidade. Disso extrai-se que se veda através da igualdade como solidariedade a discriminação negativa. Já as discriminações positivas, que são aquelas consubstanciadas em ações afirmativas constitucionalmente adequadas, são autorizadas e, inclusive, fomentadas. Por oportuno que se diga que também a discriminação não é conceitual, mas sim contextual (em um contexto o mesmo fundamento de discriminação pode configurar-se negativo/ilegal e em outro positivo/legal) (MELLO, 2010, p. 37-43). No dizer de Comparato (1993, p. 77-78):

\begin{abstract}
Os críticos que assim se pronunciam parecem desconhecer o fato óbvio de que objeto da isonomia é a igualdade de normas, enquanto as chamadas liberdades materiais têm por objetivo a igualdade de condições sociais. No primeiro caso, a igualdade é um pressuposto de aplicação concreta da lei; ao passo que, no segundo, ela é uma meta a ser alcançada, não só por meio de leis, mas também pela aplicação de políticas ou programas de ação estatal. Não há, pois, por que pretender apagar os escamotear as desigualdades sociais de fato entre homens, com a aplicação da isonomia.
\end{abstract}

Afirmar que a igualdade é contextual e não conceitual importa em abrir mão de conceitos engessados acerca da igualdade e em perceber que a assertiva "todos são iguais e devem ser tratados igualmente de acordo com suas diferenças" só faz sentido se observada em uma perspectiva holística, com o direito, mas também para além do direito - uma vez que este não se retroalimenta -. Asseverar que alguém é igual ou que é tratado com discriminação não depende de uma abstração jurídica, mas sim de uma contextualização temperada por critérios de outras searas, como a história, a sociologia, a psicologia, a cultural, a economia e a antropologia.

\title{
3 Ações afirmativas e cotas
}

De início é necessário realizar algumas ancoragens. Embora a ideia de ações afirmativas possa remeter diretamente ao direito fundamental à igualdade e à solidariedade, é preciso ter em mente que tais ações vinculam-se igualmente aos preceitos da dignidade, da liberdade e da justiça social de modo bastante claro. Ainda assim, o enfoque dedicado neste estudo será voltado majoritariamente (mas não exclusivamente) para o direito fundamental à igualdade e à solidariedade. Além disso, sabe-se que a questão envolve diversos enfoques que, na medida do 
possível, serão considerados ao lado da análise jurídica que será prevalente. Por fim, sabe-se a ideia de cotas toca diversos setores e minorias, de forma que a análise terá como vertente uma visão mais geral (ainda que escorada na questão racial e universitária).

O estudo das ações afirmativas, dada a multiplicidade de enfoques que pode receber, carece ser pontuado por linhas nevrálgicas que serão seguidas ao longo do texto. Assim, adotase uma ideia mais ou menos geral do que venham a ser ações afirmativas, vinculando-se à noção de que se tratam de variadas medidas focais, de origem privada ou pública, de norte preventivo à violação de direitos, temporárias, voltadas para o combate da desigualdade e para a equidade (social, política, jurídica, econômica) dos grupos lidos como minorias - não exclusivamente no sentido quantitativo, mas notadamente no aspecto sociocultural adstrito à discriminação - em face dos grupos majoritários, em termos de direitos e acesso a direitos.

O Grupo de Estudos Multidisciplinares da Ação Afirmativa, da IESP, traçou um conceito contemporâneo do que possa ser entendido como ação afirmativa, advogando que as:

\begin{abstract}
Ações afirmativas são políticas focais que alocam recursos em benefício de pessoas pertencentes a grupos discriminados e vitimados pela exclusão sócio-econômica no passado ou no presente. Trata-se de medidas que têm como objetivo combater discriminações étnicas, raciais, religiosas, de gênero ou de casta, aumentando a participação de minorias no processo político, no acesso à educação, saúde, emprego, bens materiais, redes de proteção social e/ou no reconhecimento cultural. [...] Sob essa rubrica podemos, portanto, incluir medidas que englobam tanto a promoção da igualdade material e de direitos básicos de cidadania como também formas de valorização étnica e cultural. [...] No debate público e acadêmico, a ação afirmativa com frequência assume um significado mais restrito, sendo entendida como uma política cujo objetivo é assegurar o acesso a posições sociais importantes a membros de grupos que, na ausência dessa medida, permaneceriam excluídos (GEMAA, 2011).
\end{abstract}

As cotas, por seu turno, passam a representar uma "espécie" de ação afirmativa, sendo muito provavelmente a mais famosa (PAULA, 2004). As cotas representam a reserva de um determinado percentual ou número de vagas (na universidade, nos postos de trabalho, na política e em outras atividades) para pessoas integrantes de um certo grupo minoritário (negros, LGBT, pobres, mulheres, deficientes, nativos, crianças, idosos, dentre outros), em razão desta condição ser reconhecida como uma vulnerabilidade cultural alvo de discriminação social e/ou institucional. Elas têm por objetivo evidentes coibir e eliminar a discriminação, induzir transformações sociais, culturais, econômicas, legais e políticas e efetivar a ideia da diversidade sob as luzes da igualdade e da solidariedade (CAVALCANTE, 2007, p. 48-78). 
O debate acerca das ações afirmativas, não obstante, no Brasil, tenha sido midiatizado na última década, remonta suas origens no Estado norte-americano, desde meados de 1960 (em que pese a expressão tenha sido utilizada pioneiramente em 1935 (GUIMARÃES, 2009, p. 170)), envolvendo conflitos raciais, especialmente. No período, abriram-se os trabalhos institucionais em prol das ações afirmativas com base em noções anti-discriminatórias (color blind), no espectro de que "o poder público não poderia estabelecer tratamentos desiguais salvo mediante alguma diferenciação satisfatória razoavelmente relacionada ao objeto da regulamentação" (MENEZES, 2001, p. 61), repetindo-se, pois, a lógica da igualdade meramente formal. Na sequência, advieram as políticas de tratamento preferencial, bem como políticas fixando espécies de cotas rígidas (blind quota) para postos de trabalho e acesso à educação (RODRIGUES, 2007, p. 93-97).

Mais marcante juridicamente nesse cenário foram três decisões norte-americanas de cunho constitucional envolvendo a $14^{\mathrm{a}}$ emenda, a qual anota o direito de "igual proteção das leis" sob o viés da igualdade. A primeira delas, na Suprema Corte, em 1978, no caso Bakke, onde o voto vencedor do magistrado Lewis Powel sustentou que, preferências raciais são possíveis como critério de seleção ao ensino superior se a sua finalidade for a de aumentar a diversidade racial e não for o único elemento de análise (DWORKIN, 2005, p. 581). Tal decisão fixou o atual precedente nesta matéria. A segunda decisão, através do Quinto Tribunal Itinerante de Apelação, deu-se no caso Hopwood, em 1996, onde, em tese - pois há celeuma em contrário -, cogitou-se a derrubada do precedente do caso Bakke (DWORKIN, 2005, p. 581). E, mais recentemente, em 2003, no caso Grutter, onde a Suprema Corte entendeu que o sistema de seleção poderia considerar o fator raça para admissão de alunos - ratificando o precedente Bakke.

O caso de Cheryl Hopwood é singular. Na época, era uma jovem que intentava ingressar na Universidade do Texas. Considerada pobre e de etnia branca, a moça atingiu um desempenho satisfatório, em termo de média acadêmica, para ingressar na faculdade de Direito. Contudo, não foi aceita, em razão do sistema de cotas raciais adotado pela Universidade, na faculdade de Direito. Alguns dos candidatos selecionados, aliás, obtiveram médias inferiores a dela. $\mathrm{O}$ caso foi levado ao Poder Judiciário e o Quinto Tribunal Itinerante de Apelação, por 3 votos a 2, entendeu que o sistema de cotas da Universidade do Texas violava a $14^{\mathrm{a}}$ emenda constitucional (DWORKIN, 2005, p. 545).

O caso Hopwood tornou-se famoso por reascender e condensar os principais argumento contemporâneos no que trata de ações afirmativas e cotas em matérias gerais, ainda que tenha 
se dado no âmbito racial de discussão. Pode-se asseverar que o debate demanda o conhecimento de duas situações gerais, as quais, por seu turno, trazem argumentos de ordem moral e argumentos de cunho jurídico. Os dois aspectos mencionados são: (a) as ações afirmativas ou as cotas são inconstitucionais? E (b) a ação afirmativa produz mais mal do que bem (porque estigmatiza o grupo minoritário como inferior e produz discriminação reversa)? (DWORKIN, 2005, p. 549).

Michael Sandel (2012, p. 211), ao tratar das cotas raciais, sintetiza ao afirmar que se argumenta em favor das cotas vendo-as como mecanismo para: 1) corrigir as distorções proporcionada pelos testes padronizados; 2) compensar o passado e; 3) promover a diversidade.

Para o primeiro item, o autor americano assevera que as avaliações de praxe (provas vestibulares, por exemplo) deveriam levar em consideração o modelo ensino, as escolas e os antecedentes sociais, culturais e econômicos dos candidatos ao lado de seus méritos acadêmicos dos alunos. Sugerem certos estudos, que em um exame (vestibular, por exemplo) 7 pontos de um aluno advindo de uma escola e de uma família/cultura que não prestigiava o estudo vale mais que os mesmos 7 pontos de um aluno saído de uma escola e de uma família/cultura que fomentava o estudo. Tal argumento, todavia, não coloca no cerne do debate a questão de a avaliação deva ser mais ampla, para além da meritocracia, envolvendo a análise do futuro sucesso acadêmico. Trata-se, na verdade, de mera retificação da forma de avaliação (SANDEL, 2012, p. 211).

No segundo item, tem-se a afirmação de que as minorias assim o são consideradas por razões e fatos historicamente vividos e razões "naturalizadas" na cultura (escravidão, perseguições, discriminações sociais e institucionais). Logo, as cotas seriam uma forma de compensar todos os prejuízos sofridos por uma minoria (enquanto grupo) no passado cujos reflexos atingem pessoas do tempo presente. Assim, por exemplo, os negros que foram escravizados tiveram inúmeras possibilidades tolhidas e isso veio a se perpetuar nos seus descendentes e a se naturalizar no imaginário social, na cultura e na sociedade (questões como negros viverem em periferias, serem mais pobres, menos escolarizados, mais voltados para trabalhos braçais, etc.). Tal argumento é atacado, pois, alega-se que os beneficiários não são aqueles que sofreram os danos diretamente e os "prejudicados" não são aqueles responsáveis pelos danos. No mesmo sentido, questiona-se se haveria diferença entre um branco rico (supostamente beneficiado direta ou indiretamente pelas contingências históricas) arcar com o sistema de cotas e um branco pobre (supostamente não beneficiado direta ou indiretamente pelas contingências históricas) também arcar. Ainda, há acusação que tal versão acabaria fazendo com 
que um negro rico, eventualmente, ingressasse na vaga de um branco pobre. Ademais, advogase que, compensam-se as avarias de um "grupo" a partir de interdições a uma "pessoa" (já que as cotas são para os negros em detrimento de um candidato e não dos brancos) (SANDEL, 2012, p. 212).

Dos itens, talvez o mais questionável seja esse, o de compensação histórica, não apenas porque é polêmico, mas porque coloca o foco no passado e faz com que o presente seja considerado com um período oco de sentido para as pessoas que o vivem. Isso porque, quando se move o foco para os grupos, impondo-lhes direitos e deveres de um para com o outro, desconsidera-se os planos e projetos das pessoas individualmente falando, as quais passam a figurar como objetos pelos quais se indenizará o atos do passado.

Já o terceiro item, voltado para a promoção da diversidade, não põe no debate a responsabilidade para com o passado ou a prioridade no tratamento de uma minoria. Afirma que é de interesse público o atingimento do interesse coletivo de formatar uma sociedade plural (fundada na alteridade) e democrática. Logo, quanto maior for a diversidade presente em cada ambiente, proporcionalmente amplos serão os conteúdos e perspectivas intelectuais e culturais envolvidas. Para tanto, aduz-se ser igualmente desejável que haja diversidade nos cargos de liderança e representação (no caso Hopwood, esse foi o argumento levantado pela Universidade do Texas, ao defender que sua missão era formar juristas advindos das minorias raciais para ocupar cargos superiores). As críticas a tal posição são de cunho ideológico e prático. De cunho prático porque questiona-se a efetividade desta medida para tornar a sociedade mais plural e para reduzir o preconceito (ou seja, não afirma que as cotas são injusta, apenas que não se prestam para o resultado buscado) (SANDEL, 2012, p. 214).

A crítica de ordem ideológica funda-se na ideia de que, por mais que as cotas atinjam seu objetivo (diversidade), isso se dará por meio de critérios que estão além do controle dos candidatos, já que nenhum deles escolheu ser negro/branco, homossexual/heterossexual, rico/pobre, etc., tornando-se as admissões embasadas nestes critérios violadora de direitos individuais dos candidatos preteridos. Para um utilitarista isso não faria muita diferença. Porém, para outros, há uma clara violação de direitos. Elaborando um contra-argumento, Dworkin (1977) irá afirmar que é comum objetarem-se as cotas para fins de diversidade em dois sentidos: 1) afirmando que elas violam o direito das pessoas a serem julgadas pelo seu mérito (acadêmico, profissional, etc.); 2) que elas violam o direito das pessoas não serem julgadas por questões que estão além de seu controle. E, mais, irá questionar: seria isso um direito? ${ }^{4}$ 
Quanto ao mérito, irá perceber-se ser uma singularidade ideológica questionável, típica das sociedade meritocráticas, especialmente, pois, de modo rude, afirma que os ricos são ricos porque mereceram mais que os pobres; que os aprovados no vestibular assim o foram porque são mais inteligentes ou estudaram mais. Ledo engano. Quando muito tais esforços/condições apenas aumentam as probabilidades de sucesso. Note-se que a própria ideia de mérito não

\footnotetext{
${ }^{4}$ Deve-se lembrar que o sistema de ingresso nas Universidades norte-americanas é diferente do modelo brasileiro de vestibular no qual efetivamente o conhecimento, mérito acadêmico (a nota) é o critério de ingresso. $\mathrm{O}$ questionamento de Dworkin se mantém, todavia, em outros âmbitos, como a pós-graduação ou entrevistas de emprego.
} 
possui um conteúdo específico e que eventual conteúdo atribuído nunca será puro (GUIMARÃES, 2009, p. 178), uma vez que os métodos de avaliação foram elaborados em um ambiente "não-puro" (preconcebido com inúmeras questões igualmente pré-anotadas com "naturais"). Crer que as melhores oportunidades e os melhores cargos são "prêmios" pra os merecedores é uma forma de vender a ideia de competição e mascarar os critérios avaliativos (muitos discriminatórios) subjacentes ao mérito. Além disso, para elucidar o critério de mérito utilizado (no Brasil) é razoável ponderar: no caso das Universidades, o critério de ingresso deve ser o mérito do conhecimento do candidato (sua nota no vestibular) ou o mérito do resultado de uma avaliação holística de suas capacidades para ser um bom profissional na área que se propõe cursar (diante da sua função social enquanto profissional)?

Ao lado disso vale mencionar que a noção senso comum de mérito obsta a solidariedade e alteridade, pois quanto maior for a crença de que o sucesso pessoal de alguém adveio exclusivamente (ou majoritariamente) de seus "méritos" individuais, proporcionalmente menor será a responsabilidade, a solidariedade social, sentida em relação à situação do outro que para trás ficou (SANDEL, 2012, p. 221). Aqui, aliás, há um exercício inverso para se testar o que se diz. Se ingressar em uma Universidade ou em uma pós-graduação de prestígio e de grande concorrência através de um sistema que não considere apenas o currículo acadêmico não diz respeito tão somente à mérito, mas muito ao elemento sorte (de ter sido positivamente considerado detentor das qualidades esperadas pelos avaliadores). Já o inverso se pode afirmar acerca da permanência e/ou conclusão, a qual tende a basear-se notadamente no mérito acadêmico. Significa dizer que a não conclusão da faculdade ou da pós-graduação, diferentemente do seu ingresso, é mais uma questão de demérito e menos de azar.

Por outro lado, quanto ao direito de ser julgado por coisas que estão fora do controle de uma pessoa, o próprio Dworkin (1977) irá elaborar o argumento de que o direito à igualdade, quando invocado em questões de discriminações sócio-históricas contra grupos minoritários, deve ser encarado como um elemento de equilíbrio, portanto positivo. Assim, a raça, por exemplo, deixa de ser um demérito, uma ofensa - como o era no passado -, para ser o elemento chave da ação afirmativa que busca reequilibrar eventuais distorções presentes (ROCHA, 2000, p. 85). Se pode-se dizer verdadeira a assertiva de que ninguém pode ser julgado por questões que estão fora do seu controle é igualmente verdadeira a noção de que ninguém pode ser prejudicado pelo passado histórico, social e cultural, do qual não fez parte (e que igualmente está fora do seu controle). Ademais, também a perspectiva de Sandel (2012, p. 294-296) é 
invocável no sentido de que eventualmente as obrigações de solidariedade tidas em comunidade não advém de escolhas particulares, mas sim de relações históricas e culturais que, no caso das cotas não se tratam de compensação do passado e sim de solidariedade presente com aqueles hoje sofrem os efeitos de ontem.

Em que pese a experiência norte-americana tenha valor histórico e, em certa medida, teórico, sendo rica em argumentos, não deve-se furtar do olhar crítico sobre a questão, mormente no que diz respeito à experiência de outros países que, para o bem ou para o mal, implementaram ações afirmativas em seus Estados (SOWELL, 2004, p. 1). Comentando a experiência norteamericana, mas também realizando uma afirmação aceitável em outros contextos, Gomes (2011, p. 49) assevera que o estabelecimento de ações afirmativas ocorreu por duas razões: 1) porque a previsão legal de vedação de qualquer discriminação não é hábil, por si só, para romper as barreiras discriminatórias socioculturais naturalizadas no imaginário social e; 2) porque, diante de tal cenário, impõem a renúncia da neutralidade estatal, em prol de uma postural de respeito, proteção e promoção dos direitos fundamentais, no caso específico, do direito à igualdade.

No caso brasileiro, muito embora a discussão sobre a "justiça" do sistema de cotas (e de ações afirmativas como um todo) permaneça presente, a questão da sua constitucionalidade especialmente no âmbito educacional - foi pacificada pelo Supremo Tribunal Federal, em 2012, ao julgar a ADPF 186. No caso, discutiam-se questões como racismo, igualdade, universalidade da educação e meritocracia. Por unanimidade, o STF considerou que o sistema de cotas - no caso raciais - era constitucional porque: a) prestigia - e não contraria - o direito fundamental à igualdade, notadamente porque o Brasil vê a igualdade em sua dupla dimensão formal e material, impondo-se uma leitura de "igualdade pela diferença" e não da "igualdade pela igualdade”; b) visando o direito à igualdade, o Estado deve-se valer tanto de ação universalistas quanto de ações afirmativas; c) as ações afirmativas não se compatibilizam apenas com o direito à igualdade, sendo coerentes com o restante da principiologia constitucional; d) em nome da diversidade e do pluralismo, previstos como princípios-objetivos fundamentais, a ideia de cotas visando o atingimento destas metas se coaduna com a Constituição Federal; e) a noção de justiça social adotada pela Constituição Federal vai além da redistribuição de riquezas, plasmando-se em reconhecer, distinguir e incorporar todos os valores culturais diversificados; e f) as ações afirmativas fundadas na discriminação reversa somente são legítimas se forem temporárias e na igual medida da persistência do quadro de exclusão social que lhe deu azo, em respeito ao Estado Democrático e ao princípio da proporcionalidade (STF, 2012). 
Diante disso, o Estado brasileiro, através do STF, respondeu a primeira das questões formuladas por Dworkin: “cotas (universitárias) são Constitucionais?”. A resposta foi positiva, na medida das condições acima indicadas. Reflexivamente afirmou que as ações afirmativas, se observadas as condições referidas, também o são.

Por sua vez, o segundo questionamento de Dworkin: “as ações afirmativas fazem mais bem ou mal?" tem sua resposta mais complexa em termos de demonstração dos resultados. Isso porque pode ser analisada sob diversas perspectivas, como incremento da diversidade, aumento da ocupação de cargos altos ou de prestígio pelo público alvo e diminuição da estratificação, das diferenças salarias, do preconceito ou da discriminação. No caso norte-americano, Dworkin, embasado em um minucioso estudo, alimentado por uma gigantesca base de dados, intitulado "The Shape of The River", de autoria de Willian Bowen e Derik Bok, entendeu que:

\begin{abstract}
Evidentemente, a ação afirmativa tem seu preço - tanto para os candidatos branco decepcionados quanto para os negros bem-sucedidos que se ofendem com qualquer desconfiança de que precisaram de uma preferência especial para ter êxito - e, sem dúvida, essa política vem provocando mais ressentimentos, em geral, mesmo que a escala desses ressentimentos continue incerta. Mas o preço moral e prático de proibila seria muito mais alto. A discriminação racial sistemática do passado gerou uma nação na qual os cargos de poder e prestígio sempre ficaram reservados para uma só raça. Não foi um ato irresponsável os críticos se oporem à ação afirmativa, argumentando que faria mais mal do que bem, quando as consequências da política ainda eram incertas. Mas seria um erro a nação proibir tal política agora, quando estatísticas e análises abrangentes demonstram de maneira óbvia seu valor. A não ser que, e até que, o estudo River seja refutado por um estudo maior e mais pormenorizado, não temos motivo para proibir a ação afirmativa universitária [...] (DWORKIN, 2005, p. 579).
\end{abstract}

A linha de Dworkin vai no sentido de que talvez a posição (e os argumentos) pró ações afirmativas venham a revelar-se não como a melhor perspectiva, mas até lá e na ausência de posição (e argumentos) melhor contra ações afirmativa, deve-se considerar o argumento favorável como mais pertinente. Em outros termos, eventualmente a posição em favor de ações afirmativas não seja a melhor, mas na falta de uma posição contrária mais aceitável, ela o é.

Tal lógica pode ser replicada no Brasil, já que estudos demonstram que as ações afirmativas têm conseguido aumentar a pluralidade e a diversidade nos diversos setores em que é proposta (RODRIGUES, 2007, p. 119-125). Mostram-se eficazes, especialmente, para quebrar as barreiras invisíveis (glass ceiling), para eliminar os efeitos prolongados (lingering effects) e para fomentar os modelos (role models) que atuam como incentivos indiretos (RODRIGUES, 2007, p. 107). Apenas para ilustrar tome-se como exemplo as ações afirmativas na Universidade (poderiam ser outras em diferente âmbito e mirando minoria diversa). 
No espaço universitário as cotas raciais e as socioeconômicas, na última década, derrubaram inúmeros dos mitos que orbitam as ações afirmativas. A Revista Fórum (CARVALHO, 2014), em matéria intitulada "Dez anos de cotas nas universidades: o que mudou?" demonstra, em síntese, que, o número de pardos e negros matriculados aumentou em comparação ao passado; os cotistas têm acompanhado e concluído o curso regularmente (não sendo intelectualmente inferiores, portanto); a nota para ingresso no vestibular dos cotistas é, em geral, menor do que a dos não-cotistas, porém a média dos cotistas ao longo do curso é superior do que a dos não-cotistas (evidenciando as discrepâncias do ensino), em geral; a evasão universitária dos cotistas é sempre menor do que a dos não-cotistas; e o sistema de cotas tende a ser mais eficaz que o sistema de "bônus" (que confere um acréscimo na nota de vestibular do aluno), porque as instituições tendem a tornar esse bônus ínfimo (meramente formal), ao passo que na cota há efetiva reserva de vaga.

\section{Considerações finais}

Demonstrou-se ao longo do estudo que as ações afirmativas tratam de variadas medidas focais, de origem privada ou pública, de norte preventivo à violação de direitos, temporárias, voltadas para o combate da desigualdade e para a equidade (social, política, jurídica, econômica) dos grupos lidos como minorias - não exclusivamente no sentido quantitativo, mas notadamente no aspecto sociocultural adstrito à discriminação - em face dos grupos majoritários, em termos de direitos e acesso a direitos. Nesse sentido, são vistas como discriminações positivas que atendem a grupos que histórica, social, cultural, institucional ou legalmente foram ou são alvo de preconceito e discriminação negativa a ponto de prejudicar ou obstar a plenitude do gozo das oportunidades e das chances do exercício da igualdade e do tratamento solidário.

Destarte, o critério de discriminação positiva utilizado pelas ações afirmativas é aquele no qual o que se "autoriza discriminar é a diferença que as coisas possuam em si e a correlação entre o tratamento desequiparador e os dados diferenciais radicados nas coisas" (MELLO, 2010, p. 34). Em termos mais objetivos, uma discriminação positiva plasmada em uma ação afirmativa tem guarida constitucional quando: a) atender a grupos lidos como minorias, que histórica, social, cultural, institucional ou legalmente foram ou são alvo de preconceito e discriminação negativa a ponto de prejudicar ou obstar a plenitude do gozo das oportunidades e das chances do exercício da igualdade e do tratamento solidário; ainda, segundo Mello (2010, p. 23/41): b) buscar o respeito, a proteção e/ou a promoção dos direitos fundamentais da minoria tutelada, por 
meio de ações ou políticas públicas temporárias; c) a lei não estabelecer como critério diferencial um elemento tão específico que singularize em definitivo apenas um sujeito; d) o critério de descriminação positiva jazer em um elemento da pessoa ou grupo tutelado, de modo que traços externos que não residam na pessoa ou no grupo não podem servir como objeto de descrímen; e) que a pessoa ou grupo desequiparado tenha efetivamente tratamento diferente, em algum sentido negativo, em relação a outra pessoa ou grupo, em razão de elemento residente na sua própria condição; e f) que haja, em abstrato, correlação lógica entre os fatos diferenciais e a adoção de um regime jurídico especial (distinto). Bem como que, em concreto, a discriminação seja positiva e atenda a algum critério de interesse constitucional voltado para o bem público.

Assim, não há como afastar-se da constatação de que o debate que envolve as ações afirmativas e, mais especificamente, as cotas para as minorias é, na verdade, uma discussão sobre o preconceito, a discriminação e a desigualdade.

Como demonstrou-se, um Estado que se diga democrático e plural precisa ler a igualdade como solidariedade, resgatando a alteridade e o espírito revolucionário que estes direitos possuíam (e possuem!). Não se nasce igual, torna-se igual, advertiu Hanna Arendt, e para tornarse igual é preciso refutar a aceitação da desigualdade como algo natural e empenhar esforços jurídicos e políticos na direção da igualdade como solidariedade.

$\mathrm{Na}$ medida em que as cotas revelaram-se ao longo do tempo positivas, seus números demonstraram um aumento significativo da emancipação e do empoderamento do público beneficiado. Portanto, aumentam-se as chances e as condições de igualdade.

\section{Referências}

ARENDT, Hanna. Origens do Totalitarismo: anti-semitismo, imperialismo e totalitarismo. São Paulo: Companhia das Letras, 1990.

AVELINO, Pedro Buck. Princípios da solidariedade: imbricações históricas e sua inserção na constituição de 1988. In: Revista de Direito Constitucional e Internacional, $n{ }^{\circ}$ 53, out/dez, São Paulo: RT, 2005. 
BAGGIO, Antônio Maria. A redescoberta da fraternidade na época do "terceiro 1789". In: Baggio, Antônio Maria (org.). O princípio esquecido: a fraternidade na reflexão atual das ciências políticas. Vargem Grande Paulista, SP: Editora Cidade Nova, 2008.

BARCELLOS, Ana Paula de. O mínimo existencial e algumas fundamentações: John Rawls, Michael Walzer e Robert Alexy. In: Legitimação dos direitos humanos. TORRES, Ricardo Lobo (Org). Rio de Janeiro, Renovar, 2007.

BOBBIO, Norberto. Estado, governo e sociedade: para uma teoria geral da política. Rio de Janeiro: Paz e Terra, 2010.

Igualdade e liberdade. 4. ed. Rio de Janeiro: Ediouro, 2000.

BONAVIDES, Paulo. O princípio da igualdade como limitação à atuação do estado. In:

Revista Internacional de Direito e Cidadania, n. 3, p. 217-229, fevereiro/2009.

BRASIL. Supremo Tribunal Federal. ADPF 186. Julgada em: 2012. Disponível em: <www.stf.jus.br>. Acesso em 25 mai. 2015.

CARDOSO, Alenilton da Silva. Princípio da solidariedade: o paradigma ético do direito contemporâneo. São Paulo: Juarez de Oliveira, 2010.

CARVALHO, Igor. Dez anos de cotas nas universidades: o que mudou? In: Revista Fórum, 2014. Disponível em: <http://revistaforum.com.br/digital/138/sistema-de-cotas-completa-dezanos-nas-universidades-brasileiras/> . Acesso em 20 mai. 2015.

CARVALHO, Kildare Gonçalves. Direito Constitucional: teoria do Estado e da Constituição, direito constitucional positivo. 16 ed. Del Rey, 2010.

COMPARATO, Fábio Konder. Igualdade, Desigualdades. In: Revista Trimestral de Direito Público. São Paulo, n. 1, pp. 69-78, 1993.

DISSENHA, Larissa Fischer Sbrissia. Uma análise da igualdade e seus efeitos no Direito Tributário Brasileiro. (Dissertação) Universidade Federal do Paraná, Programa de PósGraduação em Direito. 2014.

DWORKIN, Ronald. A virtude soberana: a teoria e a prática da igualdade. São Paulo: Martins Fontes, 2005.

Why Bakke has no case. 1977. Disponível em:

<http://www.nybooks.com/articles/archives/1977/nov/10/why-bakke-has-no-case/>. Acesso em: 25 mai. 2015.

FRISCHEISEN, Luiza Cristina Fonseca. Construção da igualdade e o sistema de justiça no Brasil: alguns caminhos e possibilidades. Rio de Janeiro: Lumen Juris, 2007.

GARCIA-PELAYO, Manuel. Las transformaciones del Estado contemporáneo. 2. ed. Madrid: Alianza, 1996.

GEMAA - Grupo de Estudos Multidisciplinares da Ação Afirmativa. Ações afirmativas. 
2011. Disponível em: <http://gemaa.iesp.uerj.br/dados/o-que-sao-acoes-afirmativas.html>. Acesso em: 01 jun. de 2015.

GOMES, Joaquim Barbosa. Ação afirmativa e o princípio constitucional da igualdade. Rio de Janeiro Renovar, 2001.

GORIA, Fausto. Fraternidade e direito: algumas reflexões. In: CASO; Giovanni et al. (Orgs.). Direito e fraternidade: ensaios, prática forense. São Paulo: Cidade Nova; Ltr, 2008.

GUIMARÃES, Antonio Sérgio Alfredo. Racismo e antirracismo no Brasil. São Paulo: Editora 34, 2009.

HOBSBAWM, E. J. A era das revoluções. 7 ed. São Paulo: Paz e Terra, 1989.

En torno a los origenes de la revolucion industrial. 23 ed. México: Siglo

Veintiuno, 1993.

MELLO, Celso Antônio Bandeira de. O conteúdo jurídico do princípio da igualdade. São Paulo: Malheiros, 2010.

MENEZES, Paulo Lucena. A ação afirmativa (affirmative action) no direito norteamericano. São Paulo: Revista dos Tribunais, 2001.

NERY JÚNIOR, Nélson. Princípios do processo civil à luz da Constituição Federal. São Paulo: Revista dos Tribunais, 1999.

OPPENHEIM, Felix E. Igualdade. In: BOBBIO, Norberto; MATTEUCCI, Nicola; PASQUINO, Gianfranco (orgs.). Trad. Carmen C. Varriale et al. Brasília: Universidade de Brasília, pp. 597-605, 1998.

PAULA, Alexandre Sturion de. Ação Afirmativa e Discriminação Reversa: Análise a partir da Instituição de Quotas para Cidadãos Negros e Pardos. In: Revista Jurídica Virtual, vo. 6, n. 61, 2004.

PERLINGIERI, Pietro. A doutrina do direito civil na legalidade constitucional. Traduzido por Maria Cristina de Cicco. In: TEPEDINO, Gustavo. Direito civil contemporâneo: novos problemas à luz da legalidade constitucional. São Paulo: Atlas, 2008.

REIS, Jorge Renato dos. A constitucionalização do Direito Privado: algumas considerações para análise. In: Revista Atos e Fatos, v. 1, p. 126-139, 2009.

ROCHA, Carmen da. A ação afirmativa - conteúdo democrático do princípio da igualdade jurídica. In: Revista Trimestral do Direito Público, n. 15, 1996.

RODRIGUES, Jorge Arthur Moojen. Políticas públicas afirmativas e o princípio da igualdade em face do preconceito e da discriminação no Brasil. Santos: Comunnicar, 2007. 
ROSANVALLON, Pierre. "O modelo da boa sociedade não é a meritocracia". 2012b. Disponível em: <http://cartamaior.com.br/?/Editoria/Internacional/\%27O-modelo-da-boasociedade-nao-e-a-meritocracia\%27\%0D\%0A/6/26370>. Acesso em: 25 mai. 2015.

La sociedad de los iguales. Trad. Maria Pons. Barcelona: RBA, 2012a.

SANDEL, Michael J. Justiça: o que é fazer a coisa certa. 9. ed. Rio de Janeiro: Civilização Brasileira, 2012.

SANTOS, Boaventura de Souza. A construção multicultural da igualdade e da diferença. In: Oficina do CES, n. 135, 1999.

SARLET, Ingo Wolfgang. A eficácia dos direitos fundamentais: uma teoria geral dos direitos fundamentais na perspectiva constitucional. 10 ed. Porto Alegre: Livraria do Advogado, 2010.

SILVA, Virgílio Afonso da. A constitucionalização do direito: os direitos fundamentais nas relações particulares. São Paulo: Malheiros, 2008.

SOWEL, Thomas. Ação afirmativa ao redor do mundo: estudo empírico. Rio de Janeiro: UniverCidade, 2004. 